\title{
Exploring the Relationship between Consumer Price Index (CPI) and Producer Price Index (PPI) in Nigeria
}

\author{
Olusola Joel Oyeleke \\ Economics Department, \\ Emmanuel Alayande College of Education, \\ Oyo, Oyo State \\ Oladele Adeyi Ojediran \\ Economics Department, \\ Emmanuel Alayande College of Education, \\ Oyo, Oyo State
}

\begin{abstract}
The study investigated the relationship between consumer price index (CPI) and producer price index (PPI) in Nigerian economy, using monthly data from 2013: 01 to 2018: 05. The study employed DF-GLS unit root test to verify the stationarity of the series. Cointegration tests involving Johansen and Engle-Granger approaches could not detect long run relationship between CPI and PPI, implying that the variables could not be substituted for each other in measuring inflation rate in Nigeria. Vector Autoregressive (VAR) technique was used to analyse the variables and the results revealed that there was no causality between CPI and PPI in Nigeria. However, the OLS result in Engle-Granger 2-step approach to cointegration provided a useful insight into the relationship between the variables. An increase in either CPI or PPI exerted a statistically significant reduction effect on the rate of other in the long run.
\end{abstract}

Keywords: cointegration, consumer price, producer price, relationship

\section{INTRODUCTION}

Price index is a measure of the percentage changes in a set of prices over time. The consumer price index (CPI) and producer price index (PPI) are designed primarily as major gauges of economic performance of nations around the world. Using a particular base year, CPI and PPI have been used as the deflators for the nominal (market or current price) Gross Domestic Product (GDP) to achieve real GDP. They are the rates used in substitute (Ulke and Ergun 2014) to measure inflation. in most developed and developing economies.

CPI, for instance, is the average price of a basket of goods and services purchased by consumers. Overtime, it is used to determine the general price level, price stability and calculate the monthly, quarterly and yearly inflation rates in an economy (Akçay, 2011). Shocks to CPI often leads to variations in bond prices, interest rates and increases market volatility (Ulke and Ergun 2014). On the other hand, PPI is the average price a producer pays for a basket of inputs (raw materials and services) needed to produce the baskets of goods and services in an economy.

The apex bank in Nigeria, the Central Bank of Nigeria (CBN), being the monetary authority in the country, has adopted inflation targeting framework since 1985 . The sole objective is to stabilise prices which have the capacity to stimulate long-run economic growth. As such, adequate inflation forecasting is expedient in order to make informed decisions about 
macroeconomic aggregates of which understanding the relationship between CPI and PPI will be of immense assistance. Although, empirical studies related to verifying the relationship between CPI and PPI are enormous for other developing countries, however, a serious attention has not been paid to the issue in Nigeria.

More importantly, the economy of Nigeria is bedevilling with inflation problem. This has distorted relative prices which has implications on the living standard of the general populace. Thus, exploring the relationship between CPI and PPI would help central banks to improve on inflation forecasting performance and define their inflation targets (Tiwari 2012; Tiwari, Suresh, Arouri, and Teulon 2014) which have capacity to curbing high inflation in the economy. Therefore, the pertinent questions answered by this study are; Is it possible to use CPI and PPI as a substitute to measure inflation in Nigeria, given the practice in other economies of the world? What is the direction of causality between CPI and PPI in Nigeria?

\section{Trends in CPI and PPI Series}

\section{LITERATURE REVIEW}

From National Bureau of Statistics (2018), the data showed that in January 2013, the Consumer Price Index (CPI) was 96.82\%, while the Producer Price Index (CPI) was 106\%. During the same year, in June, while the CPI was $98.86 \%$, PPI was $99.2 \%$. This showed a slight difference between the two indices. By December 2013, CPI had marginally increased to 99.64\% and PPI also increased a bit to $100.2 \%$. In January 2015, when the general election was approaching, the CPI rose to 102 . 79\%, while in the same month i.e. January 2015, PPI decreased to $93.6 \%$ from $108.3 \%$ recorded for December of preceding year i.e. 2014. From September, 2015 to October 2017, on average, CPI was around 103\% and similarly, over the same period, PPI was around 75\%. Finally, from January 2018, while CPI was 108.88\%, PPI stood at $94.5 \%$ and in the month of May 2018, CPI slightly increased to $109.60 \%$, but PPI decreased to $85.6 \%$.

Figure 1 showed the trends of consumer price index (CPI) and producer price index (PPI) in Nigeria from January 2013 to May 2018. From the figure below, it was shown that CPI was, on average of five months, stable between 2013 to 2014 during the study period. It was shown that from early 2015 i.e. the 25 th month, CPI began to rise consistently until 28th month when the curve drifted down a bit. The period witnessed the general election that ushered in Buhari's administration.

On the other hand, in the same period, PPI was consistently fluctuating and rose to its peak late 2014, which was the close of the second year. The peak was followed by sudden decline. This decline was due to the industrial bailout disbursed by Jonathan's administration when the election approaching. The decline of CPI from early 2015 made the CPI to maintain its persistent lead over PPI. The PPI, though consistently fluctuating, conspicuously below the CPI and the trend remained the same throughout the entire period. 


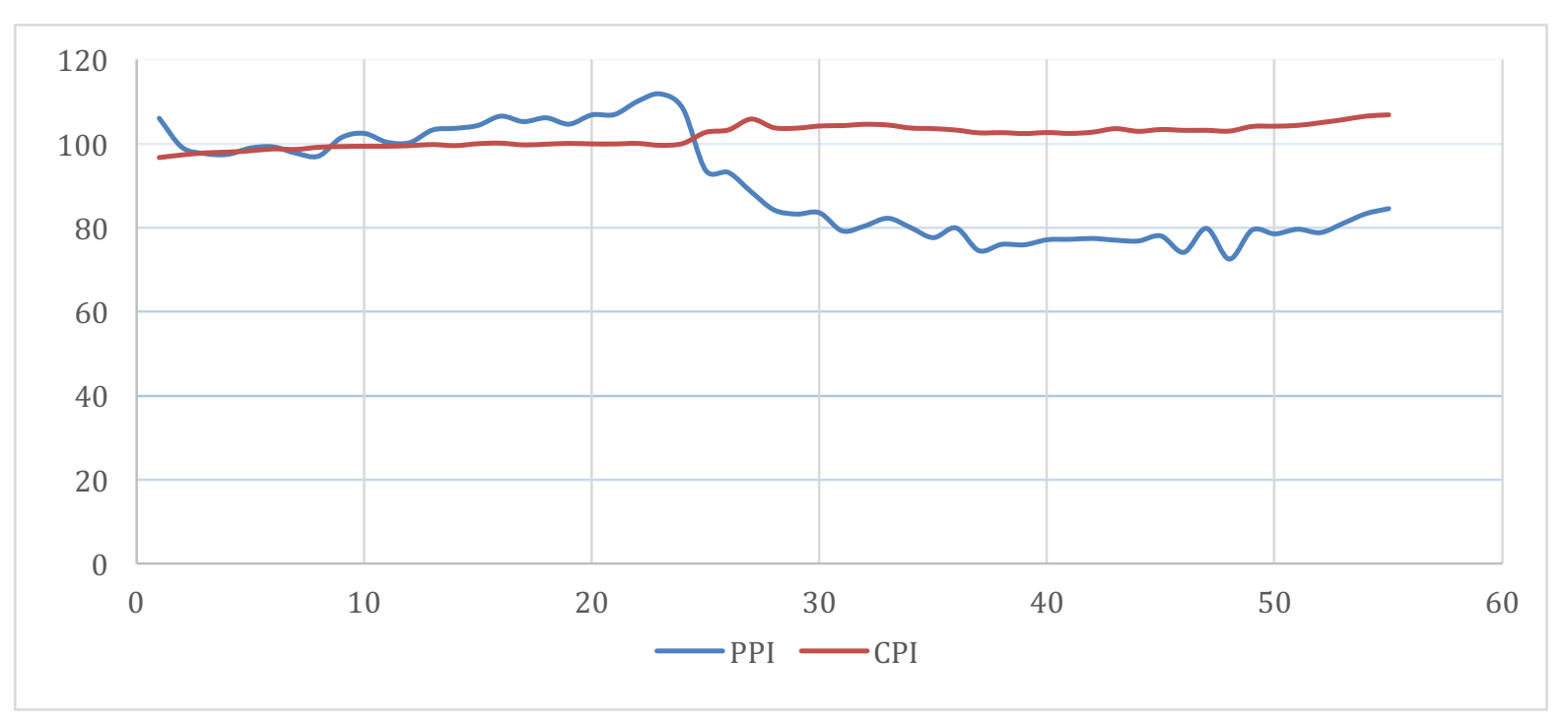

Fig. 1. Trends of CPI and PPI in Nigeria

\section{Theoretical Literature}

From theoretical view point, two basic approaches are suggested about CPI and PPI relationship; demand side approach and supply side approach. The argument from supply side approach maintains that PPI and CPI are connected through production mechanism. Economists on supply side of the debate believe that raw materials are inputs in the production process of intermediate goods, which in turns are heavily relied on as inputs for production of final goods. Increase or decrease in prices of raw materials would therefore passes through to prices of intermediate goods and lastly to final goods which the consumers consume to derive satisfaction. Through this chain, changes in PPI cause CPI to vary as well (Akçay, 2011).

Given the demand side approach, the economics theorists emphasise that the demand for final goods and services drives the demand for their production inputs. This implies that the cost of their production reflects the opportunity cost of raw inputs and intermediate goods, which in turn shows the demand for the final goods and services (Caporale, Katsimi and Pittis, 2002), thus, variation in CPI leads to changes in PPI.

\section{Empirical Literature}

Several studies have examined the relationship and/or causality between CPI and PPI in many countries over different periods of time with variant techniques. While some studies have examined whether causality exist between CPI and PPI, some have verified the period when causality occurs i.e. whether the causality is in the long run or the short run. Colclough and Lange (1982) assessed the direction of causality between PPI and CPI in United States (US), using Sims and Granger causality tests and confirmed that causality ran from consumer prices to producer prices in the economy. Jones (1986), investigated causality between PPI and CPI in US. VAR method of analysis was used to investigate the short and long-run relationships between the variables and the study found the evidence of bidirectional causality.

Similarly, Caporale, Katsimi and Pittis (2002) examined the relationship between PPI and CPI for G7, using monthly data from January 1976 to April 1999. The authors employed Toda and Yamamoto approach (1995) VAR systems. The study concluded that unidirectional causality ran from PPI to CPI in France and Germany, but causality was bidirectional in Italy, Japan, the United Kingdom and US. In Canada, however, no causality was detected. Akdi, Berument and Cilasun, (2006) investigated the long and short run relationships between Wholesale Price 
Index (WPI) and Consumer Price Index (CPI), using monthly data from 1987:01 to 2004:08 in Turkey. The authors used three different methods to examine the long run relationship between the variables. Their findings revealed that Engle and Granger (1987) and Johansen (1988) conventional tests gave mixed results while periodogram method suggested no cointegration between PPI and CPI. However, a short- run relationship between WPI and CPI was found.

In another development, Ghazali, Yee and Muhammed (2008) studied the relationship between PPI and CPI, using monthly data from January 1986 to April 2007 in Malaysia. The authors employed both Engle-Granger Vector Error Correction Model (VECM) and Toda and Yamamoto no-causality test. The results of both approaches showed that a unidirectional causality running from PPI to CPI was found in Malaysia. Liping, Gang and Jiani (2008) analysed the relationship between PPI and CPI with monthly data for China. The authors found a unidirectional causality between two indices, running from CPI to PPI.

In Pakistan, Shahbaz, Awan and Nasir (2009) assessed the relationship between PPI and CPI using monthly data. The authors used ARDL bounds testing and Johanson cointegration approach to determine the long run relationship between PPI and CPI. Also, the authors used Toda and Yamamato approach (1995) to determine causality between PPI and CPI. Their results gave the evidence of long run relationship between producer and consumer prices. They also found that there was bidirectional causality but it was stronger from producer to consumer prices. Sidaoui, Capistrán, Chiquiar, and Ramos-Francia (2010) investigated the relationship between PPI and CPI for Mexico. Engle-Granger Vector Error Correction Model (VECM) was used to determine short run and long causality between PPI and CPI. It was revealed that causality ran from the PPI to the CPI in the long run but in the short run there was no causality between PPI and CPI.

Akcay (2011), employing monthly data from August 1995 to December 2007 for five European countries, explored the causality between CPI and PPI. The study used Toda and Yamamto Causality Test (1995). The empirical results showed that in Finland and France, PPI causes CPI to change but there was no feedback effect. However, in Germany, CPI and PPI impacted each other and exhibited a bidirectional causality relationship, while in the Netherlands and Sweden, no significant causal relationship was found. Ulke and Ergun (2014) analysed the relationship between the Consumer Price Index (CPI) and the Producer Price Index (PPI) in Turkey. The authors used Johansen's cointegration test to examine the long run, short run relationship. The causality relationship was verified with Vector error correction (VEC) model. The results showed that there was an existence of long and short run relationship, while a unidirectional long run causality ran from CPI to PPI. Hence, the result suggested demand pull inflation in Turkey.

From empirics, four different evidence abound about the direction of causality between PPI and CPI. While some empirical studies suggest that causality run from CPI to PPI (see Liping, Gang and Jiani, 2008), some provide the evidence that the reverse holds (Caporale, Katsimi, and Pittis, 2002 and Ghazali, Yee and Muhammed, 2008). Also, enormous studies find bidirectional causal relationship between CPI and PPI (Shahbaz, Awan and Nasir, 2009) in different economies and some others maintain no causality between the variables (Berument, Cilasun, and Akdi, 2006). Thus, a controversy exists.

\section{DATA AND METHODOLOGY}

This study used monthly PPI and CPI data over the period 2013: 01 to 2018: 05, which means we dealt with 65 observations. The period was so crucial in Nigeria, given the fact that both oil 
boom and glut in international market were experienced within the period. Also, the period witnessed down turn in economic growth (recession) from early 2016 to early 2017 and its recovery which have implications on both consumer prices and producer prices in the economy. The data on CPI and PPI were obtained from the National Bureau of Statistics published in July, 2018. The series were transformed into natural logarithm to devoid them of randomness prior to analysis. In order to explore the relationship between CPI and PPI in Nigeria, this study adopted Ulke and Ergun (2014) method, using unrestricted Vector Autoregressive (VAR) model that places no restriction on the economy. Similarly, VAR does not require any theoretical prediction about the ordering of variables, therefore takes all the variables as endogenous and permits to test the direction of causality.

This study, however went further by employing Engle-Granger 2-step as another test of cointegration instead of relying on Johansen cointegration test alone. We specified Vector Autoregressive (VAR) model thus:

$$
\mathrm{U}(\mathrm{VAR})=\left(C P I_{t}, P P I_{t}\right)
$$

Where $C P I_{t}$ represented consumer price index, while $P P I_{t}$ stood for producer price index. More explicitly, equation (1) could be expressed as VAR (p),

$$
y_{t}=\delta+A_{1} y_{t-1}+A_{2} y_{t-2}+A_{3} y_{t-3}+\ldots+A_{q} y_{t-p}+B x_{t} \varepsilon_{t}
$$

Where $y_{t}=\left(C P I_{t}, P P I_{t}\right)$, i.e. $y_{t}$ was a $2 \times 1$ dimensional Vector of the endogenous variables, $\delta$ was a $\times 1$ dimensional Vector of constants, $A_{1} \ldots . . A_{q}$ was $\mathrm{k} \times \mathrm{k}$ dimensional autoregressive coefficient matrixes and $\varepsilon_{t}$ represented $\mathrm{k}$ dimensional stochastic error term that followed iid i.e. identically independent distribution. Writing equation (2) in first difference model,

$$
\Delta y_{t}=\lambda y_{t-1}+\sum_{i=1}^{p-1} \Gamma_{i} \Delta y_{t-i}+B x_{t}+\varepsilon_{t}
$$

Where $\lambda=\sum_{i=1}^{p} A_{i}$ and $\Gamma_{i}=-\sum_{j=t+i}^{p} A_{i}$

In this model $y_{t}$ denoted consumer price index (CPI) and producer price index (PPI) variables. They were shown in a k-vector. If the coefficient matrix $\lambda$ has reduced rank $0<\mathrm{r}<\mathrm{k}$, then there exists $\mathrm{k} \times \mathrm{r}$ matrices $\alpha$ and $\beta$ each with rank r such that $\lambda=\alpha \beta^{\prime}$ and $\beta^{\prime} y_{t}$ is I( 0$)$. $\mathrm{r}$ was taken as the number of the cointegrating relations. Also, $\beta$ was the cointegrating vector. It should be noted that if the rank of $\lambda$ was equal to zero, there was no combination of $y_{t}$ series, that is, stationary. Hence, no cointegration existed between the variables.

However, if there was a cointegratiing equation(s) between CPI and PPI, the elements of $\alpha$ were the adjustment parameters in vector error correction model (VECM). Then VAR system could be taken as representing VECM for long run endogenous variables, thus we had the following equation;

$$
\Delta y_{t}=\phi+\alpha \beta^{\prime} y_{t-1}+\Gamma_{i} \Delta y_{t-i}+B x_{t}+\psi E C M_{(-1)}+\varepsilon_{t}
$$

Where $\phi$ represented the intercept in the system and $\psi$ was the coefficient of error correction term derived from long term cointegrating relationship. More explicitly, equation (4) was stated thus; 


$$
\begin{aligned}
& \Delta l i n C P I_{t}=\phi_{1}++\theta_{i} \sum_{i=0}^{p} \Delta \operatorname{linCPI} I_{t-i}+\theta_{i} \sum_{i=1}^{p} \Delta l i n P P I_{t-i}+\tau E C M_{t-1}+\mu_{t} \\
& \Delta l i n P P I_{t}=\beta_{1}+\lambda_{i} \sum_{i=0}^{p} \Delta \operatorname{lin} P P I_{t-i}+\lambda_{i} \sum_{i=1}^{p} \Delta \operatorname{linCPI} I_{t-i}+\Omega E C M_{t-1}+\mu_{t}
\end{aligned}
$$

Where $\Delta$ represented first difference operator, i stood for lag length, $\mathrm{P}$ was the maximum lag length distribution and $E C M_{t-1}$ was the $h t h$ error correction term. It was obtained from the residuals generated from hth co-integrating equations. $\tau, \beta, \theta$ were $\Omega$ the coefficients to be estimated. Equations (5) to (6) could be written in compact form;

$$
\Delta X_{t}=\mu+\sum_{i=1}^{p-1} \Gamma_{i} \Delta X_{t-i}+\Pi X_{t-p}+\varepsilon_{t}
$$

In line with the suggestion of Pinn, Kogid,, Mulok, Mansu, and Loganathan (2011), however, if there was no cointegration between the variables, then the ECM model without error correction term would be specified as follows;

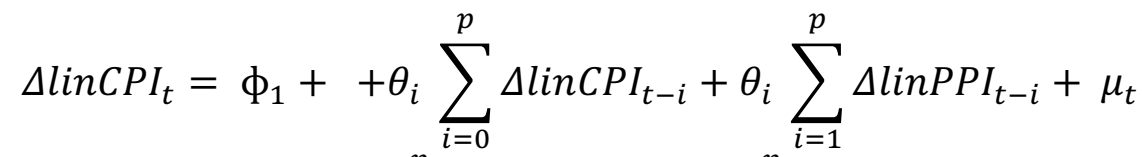

$$
\begin{aligned}
& \Delta \operatorname{lin} P P I_{t}=\beta_{1}+\lambda_{i} \sum_{i=0}^{p} \Delta \operatorname{lin} P P I_{t-i}+\lambda_{i} \sum_{i=1}^{p} \Delta \operatorname{lin} C P I_{t-i}+\mu_{t}
\end{aligned}
$$

All the coefficients of the short-run equation were the coefficients relating to the short-run dynamics of the model's convergence to equilibrium.

\section{RESULTS AND DISCUSSIONS}

From Table 1, the results of unit root test showed that, using Dicky Fuller-GLS test, both consumer price index (CPI) and producer price index (PPI) were not stationary at level i.e. I(0), but were first difference variables i.e. I(1) process at $1 \%$ and $10 \%$ significance level respectively. We concluded, therefore, that CPI and PPI were first difference variables at 1\% and $10 \%$ significance levels. It was realised that the method of unit root test, that is, DF-GLS technique was capable of detecting the presence of the unit root in the variables, especially when small samples were included Elliott, Stock and Rothenberg (1996). Thus, the method was considered for the analyses in this study. In this case, the orders of integration of the two variables were the same i.e. I(1) process.

\begin{tabular}{lcll}
\hline Variables & \multicolumn{3}{c}{ DF-GLS } \\
\hline LCPI & Level & First Difference & Decision \\
LPPI & 1.004978 & $-7.389882^{*}$ & $\mathrm{I}(1)$ \\
\hline
\end{tabular}

Table 1: Results of Unit Root Test. ${ }^{*}{ }^{* * *}$ indicated $1 \%$ and $10 \%$ significant levels respectively.

According to Engle and Granger, (1987), only variables with the same order of integration i.e. I (1) could be tested for cointegration which represents their long run relationship. Then, we 
analysed their cointegrating relationship, using Johansen cointegration test approach. EngelGranger 2-step method was also employed as a robustness check.

\section{Cointegration Test}

Table 2 presented the Johansen cointegration test result. The results showed that no cointegration i.e. long run relationship could be found between CPI and PPI. This implied that the variables did not move together (converge) in the long run, given Trace and Maximum Engen statistics and based on 5\% significant level. It was, therefore, concluded that the null hypothesis of no cointegrating between CPI and PPI was not rejected, using Mackinnon-HaugMichel (1999) p-values. The policy implication of the result was that we could not use either

\begin{tabular}{lllll}
\hline Trace Test & 5\% Critical Values & Max-Engen Stat. & 5\% Critical Values & Hypotheses \\
\hline 2.581067 & 15.49471 & 2.495124 & 14.26460 & $\mathrm{r}=0$ \\
0.085943 & 3.841466 & 0.085943 & 3.841466 & $\mathrm{r} \geq 1$ \\
\hline
\end{tabular}

Table 2. Johansen Maximum Likelihood Cointegration Test Result. * denoted rejection of the hypothesis at the 5\% level of significance based on MacKinnon-Haug-Michels (1999) p-values

of the two variables as substitute for measuring inflation rate in Nigeria. To verify this results, Engel-Granger 2-step cointegration test was employed. The results were pasted in Tables 3 and 4 respectively. As the name of the cointegration approach suggests, the first step was to run OLS regression and the residuals generated from the OLS would be tested against presence of unit root at levels.

According to Asteriou and Hall (2007), if the residuals are stationary at levels, we can conclude that there is existence of conintegration between the variables. However, if the residuals are not stationary at levels i.e. not I(0) process, then we conclude that there is no long run relationship between the variables of interest. In this case, two long run (OLS) models were used. While model 1 had CPI as dependent variable, model 2 had PPI as dependent variables given that theory did not specify either as exogenous. Table 3 contained the results for the two models.

\begin{tabular}{llllllc}
\hline & \multicolumn{2}{c}{ Model 1 CPI (dept) } & \multicolumn{3}{c}{ Model 2 PPI(dept) } \\
\hline Variable & Coeft & Stand. Err. & t.stat. & Coeft & Stand. Err. & t.stat. \\
\hline PPI & -0.170 & 0.029 & -5.848 & & & \\
& & & {$[0.000]$} & & & -5.848 \\
CPI & & & -2.072 & 0.354 & {$[0.000]$} \\
& & & & & 8.308 \\
C & 118.109 & 2.629 & 44.923 & 302.972 & 36.466 & {$[0.000]$} \\
& & & {$[0.000]$} & & & \\
\hline
\end{tabular}

Table 3. OLS Results

The results of the tests of the unit root in residuals generated from OLS estimation shown in Table 4 revealed that the residuals were not stationary at levels i.e. I(0), and we, therefore, could not reject the null hypothesis of the presence of unit root at $10 \%$ significance level. Again, we concluded that there was no long run relationship between the variables. These results agreed with the findings of Akcay (2011) for France, Finland, Sweden and

\begin{tabular}{lcl}
\hline Variable & DF-GLS & Decision \\
\hline CPI (resid.) & 0.049468 & No stationary \\
PPI (resid.) & -1.412321 & No stationary \\
\hline
\end{tabular}

Table 4. Unit Root Test in Residuals, using DF-GLS. * indicates rejection of null hypothesis 
Netherlands, Berument, Cilasun, and Akdi (2006) for Turkey, but in contrast with Ulke and Ergun (2014) who found long run relationship between CPI and PPI for Turkey.

However, from Table 3, the OLS results provided a useful insight into the long run effect of CPI on PPI and vice-versa. This equally has policy implication for Nigerian economy. Given the coefficients of CPI and PPI i.e. (-0.170) and (-2.072) respectively with the same t-statistics. ($5.848)$ and probability values (0.000), there was a negative effect of one variable over the other. Specifically, $1 \%$ increase in PPI would cause CPI to reduce by $17 \%$ monthly. Similarly, $1 \%$ increase in CPI would influence PPI to reduce by over $200 \%$ every month in the economy of Nigeria. The development indicated that as CPI increased, PPI deceased. This result lent credence to the trends of the series pictured in Fig. 1 above. It could be concluded that these two important measures of inflation rates were not determined within the economy since the economy relies much on importation of finished and intermediate goods for production. This result was consistent with Adedokun (2018) who argued that inflation was more of exogenously determined through undue demand for foreign products which drove up exchange rate.

Once we could not find the equilibrium between the variables, we resorted to testing for short run effect between CPI and PPI, using equations (7) and (8) without specifying error correction term (VAR). However, there was a need to determine the number of lag length to be included in the model, hence we proceeded to determining the number of lag length through lag length order selection criteria. The results of lag length order selection criteria and confirmed by lag length exclusion test were pasted in appendix. The results showed that all the criteria i.e. final prediction error (FPE), Akaike information criterion (AIC), Schwarz information criteria (SIC) and Haman-Quinn information criteria chose 1 lag maximum.

The VAR results were presented in two models. Model 1 contained CPI as dependent variable and model 2 had PPI as dependent variable. Table 5 contained the results. From Table 5, it was evident that, as shown by their t-statistic values, none of the variables had statistically significant effect on each other in the short run. Going by the values of R-square statistics i.e. $(0.955)$ and $(0.917)$ respectively, it could be observed that the models were well fitted. Thus, we proceeded to testing for causality between CPI and PPI, using VAR Granger Causality/Block Erogeneity tests. This was done to verify whether causality existed between

\begin{tabular}{|c|c|c|c|c|c|c|}
\hline \multicolumn{4}{|c|}{ Model $1 \Delta$ linCPI (dept) } & \multicolumn{3}{|c|}{ Model $2 \Delta \operatorname{linPPI}(\mathrm{dept})$} \\
\hline Variable & Coeft & Stand. Err. & t.stat. & Coeft & Stand. Err. & t.stat. \\
\hline$\Delta(\operatorname{lin} P P I(-1))$ & -0.135 & 0.165 & -0.817 & & & \\
\hline$\Delta(\operatorname{lin} C P I(-1))$ & & & & 0.006 & 0.009 & 0.604 \\
\hline $\mathrm{C}$ & 0.036 & 4.092 & 0.009 & 20.683 & 19.680 & 1.051 \\
\hline $\begin{array}{l}\text { R-sq. } \\
\text { F-st }\end{array}$ & $\begin{array}{l}0.955 \\
647.419\end{array}$ & $\begin{array}{r}0.917 \\
335.695\end{array}$ & Adj. R-sq & 0.953 & 0.913 & \\
\hline
\end{tabular}

\section{Table 5. VAR Results}

the variables. Since, there was no cointegration between the variables and both CPI and PPI were I(1) process, VAR Granger causality/block exogeneity causality approach was appropriate. The result of causality was pasted in Table 6. From Table 6, the results revealed that causality neither run from CPI to PPI nor from PPI to CPI. The results indicated 


\begin{tabular}{lccc}
\hline Dependent Variable: CPI & & & \\
Excluded & Chi-sq & df & Prob. \\
\hline PPI & 0.365 & 2 & 0.545 \\
All & 0.365 & 2 & 0.545 \\
Dependent Variable: PPI & & & \\
CPI & 0.667 & 2 & 0.414 \\
All & 0.667 & 2 & 0.414 \\
\hline
\end{tabular}

Table 6. Granger Causality/Block Exogeneity tests

that a price variation recorded in a particular component of the PPI would not be eventually and directly transferred to the same component of the CPI in Nigeria. Based on this results, we concluded that there was no causality between CPI and PPI in Nigeria during the period under reviewed. This result was not in contrast with the result obtained for short run analysis, where there was no significant effect between the variables. There was a similarity between this result and that of Berument, Cilasun, \& Akdi (2006)'s result for Turkey. While Berument, Cilasun, \& Akdi found short run relationship, but no cointegration between CPI and PPI, rather we found long run effect and no cointegration between the variables in Nigeria. Also, Caporale, G. M., Katsimi, M. \& Pittis, N. (2002) found no evidence of causality between CPI and PPI for Canada and Akcay (2011) for Netherlands and Sweden.

\section{CONCLUSION}

Several studies have investigated the causality between the consumer price index and the producer price index for different economies over a range of period, using various techniques. In the literature, while some studies found bidirectional causal relationship, some studies found unidirectional and others authors did not find any causality between PPI and CPI. In this study, two methods of cointegration, comprising of Johnasen and Engel-Granger 2-step approaches were employed to verify the long run relationship between CPI and PPI in Nigeria.

Also, VAR methodology of Granger causality test was employed to empirically investigate causal link between PPI, and CPI, using monthly data from January 2013 to May 2018. The cointegration test results of both Johansen and Juselius (1990) and Engel-Granger 2-step indicated that the variables were not cointegrated. This implied that we could not use CPI to predict PPI and vice versa, or either as a measures of inflation rate. The findings indicated that a price shock recorded in a particular component of the PPI would eventually and directly be transferred to the same component of CPI and vice versa in Nigeria. The empirical finding supported the theoretical stands that shocks erupted from either supply side or demand side evolved shocks to other side in the long run i.e. long run effect. However, the study could not find causality between CPI and PPI in Nigeria, a development that was in consonance with the empirical findings in many other economies.

\section{References}

Adedokun, A. (2018). The effects of oil shocks on government expenditures and government revenues nexus in Nigeria (with exogeneity restrictions). Future Business Journal, 4, 219-232.

https://doi.org/10.1016/j.fbj.2018.06.003

Akdi, Y., Berument, H., \& Cilasun, S.Y. (2006). The relationship between different price indices: Evidence from Turkey, Physica A, 360, 483-492, htt://dx.doi.org/10.1016/j.physa

Akeay, S. (2011). The causal relationship between producer price index and consumer price index: Empirical evidence from selected European countries, International Journal of Economics and Finance, 3(6), 227-232.

Caporale, G. M., Katsimi, M., \& Pittis, N. (2002). Causality links between consumer and producer prices: some empirical evidence, Southern Economic Journal, 68, 703-711, http://dx.doi.org/10.2307/1061728 
Colclough, W. G., \& Lange, M. G. (1982). Empirical evidence of causality from consumer to wholesale prices, Journal of Econometrics,19, 379-384, htt://dx.doi.org/10.1016/0304-4076(82)90012-4.

Elliott, G., Stock, J. H. \& Rothenberg, T. J. (1996). Efficient tests for an autoregressive unit root. Econometrica, 64(4):813-36. DOI: $10.2307 / 2171846$

Engle, R. F., \& Granger, C. W. J. (1988). Cointegration and error correction: representation, estimation and testing, Econometrica, 55,251-276. htt://dx.doi.org/10.2307/1913236

Ghazali, M. F., Yee, O.A., \& Muhammad, M. Z. (2008). Do producer prices cause consumer prices? Some empirical evidence, International Journal of Business and Management, 3(11), 78-82. htt://dx.dodoi.org/10.5539/ijbm.

Jones, J. D. (1986). Consumer prices, wholesale prices and causality. Empirical Economics, 11, 41-55. htt://dx.doi.org/10.1007/BF01978144.

Liping, H., Gang, F., \& Jiani, H. (2008). CPI vs PPI: Which drives which? Economic Research Journal, 43(11), $16-27$.

Pinn, K. S. C., Kogid, M., Mulok, D., Mansur K., \& Loganathan, N. (2011). Empirical analysis of employment and foreign direct investment in Malaysia: An ARDL Bounds testing approach to cointegration. Advances in Management and Applied Economics.1 (3):77-91.

Tiwari, A. K. (2012). An Empirical investigation of causality between producer's price and consumers price indices in Australia in frequency. Economic Modelling, 29, 1571-1578

Tiwari, A. K. et al. (2014). Causality between Consumer and Producer Price: Evidence from Mexico. Economic Modelling. 36, 432-440

Toda, H.Y., \& Yamamoto, T. (1995). Statistical influence in vector autoregression with possibility integrated processes, Journal of Econometrics, 66, 225-250. 


\section{APPENDIX}

\begin{tabular}{ccccccc}
\hline \hline Lag & LogL & LR & FPE & AIC & SC & HQ \\
\hline \hline 0 & -339.4450 & NA & 845.9283 & 12.41618 & 12.48917 & 12.44441 \\
1 & -203.9642 & $256.1818^{*}$ & $7.095950^{*}$ & $7.635062^{*}$ & $7.854043^{*}$ & $7.719744^{*}$ \\
2 & -202.5621 & 2.549188 & 7.805159 & 7.729532 & 8.094502 & 7.870669 \\
3 & -200.3721 & 3.822542 & 8.350925 & 7.795351 & 8.306308 & 7.992942 \\
4 & -197.6945 & 4.478925 & 8.790055 & 7.843437 & 8.500383 & 8.097483 \\
5 & -194.4799 & 5.143389 & 9.089979 & 7.871997 & 8.674930 & 8.182497 \\
6 & -193.9884 & 0.750694 & 10.40249 & 7.999577 & 8.948499 & 8.366533 \\
7 & -192.6597 & 1.932615 & 11.58006 & 8.096717 & 9.191626 & 8.520127 \\
8 & -187.7670 & 6.760798 & 11.36226 & 8.064255 & 9.305152 & 8.544120 \\
9 & -186.4775 & 1.688119 & 12.76029 & 8.162818 & 9.549702 & 8.699137 \\
10 & -181.5638 & 6.075135 & 12.62035 & 8.129592 & 9.662464 & 8.722366 \\
\hline \hline
\end{tabular}

* indicates lag order selected by the criterion

LR: sequential modified LR test statistic (each test at 5\%

level)

FPE: Final prediction error

AIC: Akaike information criterion

SC: Schwarz information

criterion

HQ: Hannan-Quinn information criterion

VAR Lag Exclusion Wald Tests

Date: 08/01/18 Time: 15:41

Sample: 2013M01 2018M05

Included observations: 64

Chi-squared test statistics for lag exclusion:

Numbers in [] are p-values

\begin{tabular}{cccc}
\hline \hline & PPI & CPI & Joint \\
\hline \hline Lag 1 & $\begin{array}{c}\text { 671.3902 } \\
{[0.000000]}\end{array}$ & $\begin{array}{c}\text { 1294.839 } \\
\text { 0.000000] }\end{array}$ & $\begin{array}{c}1931.893 \\
0.000000]\end{array}$ \\
\hline \hline df & 2 & 2 & 4 \\
\hline \hline
\end{tabular}

